\title{
O Papel do Professor como Mediador de Conflitos entre Crianças da Educação Infantil
}

Teacher's Role as Mediator of Conflicts Between Children in Childhood Education

\author{
Natalia Quinquiolo ${ }^{1}$ \\ ${ }^{1}$ Graduada em em Ciências Biológicas pela Universidade Federal de Lavras e Pós Graduada em Psicopedagogia Insti- \\ tucional. Atualmente, atua como professora na UNIPLAN - Centro Universitário Planalto do Distrito Federal
}

Recebido em 14 de setembro de 2016; Aceito em 22 de junho de 2017.

\begin{abstract}
Resumo
A escola vem sofrendo mudanças constantes em sua forma de atuação. Se antes a escola somente ensinava ao aluno saberes relativos ao conhecimento, hoje apresenta-se como um segundo local de aquisição de valores morais e conceitos de convívio social fora do ambiente familiar, principalmente no âmbito da Educação Infantil. Nesse contexto, os professores passam a assumir um novo papel, o de mediador, favorecendo a atuação da criança de forma consciente e independente na resolução de seus conflitos. Diante de tal panorama, o presente trabalho busca analisar através de uma revisão bibliográfica qual a função do professor na formação do indivíduo dentro de sua atuação como mediador de processos.
\end{abstract}

Palavras-chave: Mediação; Professor; Conflito.

\begin{abstract}
The school has undegone constant changes in the way it operates. If before school only taught the studente contentes related to knowledge, today is like a second place for the acquisition of moral values and concepts of social life, outside the home, especially in the contexto of childhood education. In this context, teachers begin to take on a new role, that of mediator, favoring the child's acting consciously and independently in resolving their conflicts. Faced with this panorama, this paper seeks to examine through a literature review which the teacher's role in shaping the individual in its role as mediator processes.
\end{abstract}

Keywords: Mediator; Teacher; Conflict. 


\section{INTRODUÇÃO}

Antigamente, a escola era vista como uma instituição detentora do saber que tinha como função primordial transmitir aos alunos o conhecimento. Com a evolução constante em que a sociedade e os seres humanos se encontram, a escola passou a ser encarada como uma extensão do ambiente familiar, onde a criança aprende não só a ler, escrever e a desenvolver seu intelecto, mas também a desenvolver sua personalidade, participando ativamente da construção de seus valores. Dentro disto, a Educação Infantil, presente como o primeiro momento da criança na escola, passa a ser considerada um importante meio para o ensino de conceitos sócio morais.

Considerando o ambiente escolar propicio para o aparecimento de conflitos, já que crianças começam ali a ter contato com outros indivíduos fora de sua casa, sejam eles adultos ou outras crianças, passa-se a ter a necessidade de professores que saibam compreender o significado construtivo do conflito na formação do ser e saibam também, mediar as situações em que estes conflitos ocorrem. Nesse sentido, os conflitos devem ser encarados não mais como negativos e sim como naturais e de grande importância para o crescimento individual e coletivo.

O professor, antes uma figura autoritária e muitas vezes arbitraria na resolução de conflitos, assume um papel de mediador, que ensina e possibilita às crianças resolverem suas diferenças, intervindo o mínimo possível para que elas aprendam a lidar com seus sentimentos e seus colegas.

A abordagem da educação para a paz e das práticas restaurativas nas escolas é fundamental para uma formação mais cidadã das nossas crianças e jovens e, por isso, entendemos que, para além do tratamento transversal desses temas nos currículos escolares, necessitamos criar verdadeiras rotinas escolares que promovam o respeito ao próximo e a resolução pacífica dos conflitos; quando se fala em paz nas escolas, fala-se em aprendizagem cooperativa, em educação multicultural, em redução de preconceitos e na criação de uma cultura de prevenção de violência (Nunes, 2011).

É importante, dentro do novo papel que a escola possui que analisemos o papel de agente formador da própria escola e dos professores, principalmente em situações conflituosas, que dão as crianças subsídios para convivência social e para o desenvolvimento individual.

O ambiente escolar e a vibrante interação de criança, professor, currículo, ambiente, família e comunidade, representam um micro-cosmo do universo: o espaço físico delimita o mundo; o sistema escolar e sua organização revelam a sociedade e as pessoas envolvidas na experiência de aprendizado formam a população (Taylor \&Vlastos, 1983).

\section{O PAPEL DA ESCOLA NO DESENVOLVIMENTO DO INDIVIDUO}

O ambiente escolar possui um papel fundamental para a formação do indivíduo, haja vista que uma criança presente na escola nos primeiros anos de vida passa desde muito cedo a ter um círculo de convívio diferente de seus pais, avós e de familiares mais próximos, círculo esse que favorece a vivência de novas experiências sociais e educacionais que contribuirão ativamente para o desenvolvimento da personalidade daquele indivíduo.

Normalmente a criança é introduzida ao mundo pela primeira vez através da escola. No entanto a escola não é de modo algum o mundo e não deve fingir sê-lo; ela é, em vez disso, a instituição que interpomos entre o domínio privado do lar e o mundo com o fito de fazer que seja possível a transição, de alguma forma, da família para o mundo (Arendt, 1992, p. 238-239). 
Santos, Prestes e Freitas (2014) ressaltam que no mundo atual, as crianças em idade pré-escolar passam mais tempo longe de casa do que em épocas anteriores e muitas são as crianças que permanecem várias horas por dia em escolas de Educação Infantil, onde convivem não apenas com adultos, mas também com seus pares. Afirmam ainda que a creche ou pré-escola, além de ser uma alternativa muitas vezes escolhida pelas famílias para o cuidado de seus filhos, possibilita a ampliação da rede de relações que promovem a socialização dos pequenos. Além do impacto no desempenho escolar e na competência social dos estudantes, a Educação Infantil desempenha um papel fundamental na formação ética e desenvolvimento moral das crianças (Dias \& Vasconcellos; 1999).

A escola é o lugar não só de acolhimento das diferenças humanas e sociais encarnadas na diversidade de sua clientela, mas fundamentalmente o lugar a partir do qual se engendram novas diferenças, se instauram novas demandas, se criam novas apreensões sobre o mundo já conhecido; em outras palavras, escola, é, por excelência, a instituição da alteridade, do estranhamento e da mestiçagem - marcas indeléveis da medida de transformabilidade da condição humana (Aquino, 1998, p. s/n).

Atualmente, o reconhecimento da criança enquanto sujeito social e histórico, detentora de direitos sociais, faz da educação infantil uma exigência social, ocupando no cenário da educação brasileira um espaço significativo e relevante (Andrade, 2010).

A Lei no 9.394 estabelece que a educação deve-se preocupar com os processos formativos que se desenvolvem nos diferentes meios que a criança está inserida, devendo-se vincular à pratica social. Isso significa que a escola deve preparar os alunos para inserção na sociedade, sendo nesse sentido, imprescindível uma educação pautada na aquisição de valores morais (Pereira,Marques \&Jusevicius; 2012).

Tida como um dos principais agentes socializadores, a escola é responsável não apenas pela difusão de conhecimentos, mas pela transmissão dos valores de uma cultura entre gerações (Martin-Baró, 1992).

Pereira e cols.(2012) em seu trabalho analisam o papel da escola e constatam que o tipo do ambiente escolar influencia diretamente no desenvolvimento afetivo, moral e cognitivo de seus alunos e que as escolar que se dedicam a proporcionar um ambiente sócio moral cooperativo, isto é, um lugar com relações de respeito mútuo, horizontais e de cooperação, que estimulam a criatividade e iniciativa dos alunos, proporcionando atividades que favorecem a troca de pontos de vista e usam sanções por reciprocidade, presenciam com maior frequência o desenvolvimento intelectual e moral de seus alunos quando comparadas aquelas com uma relação hierárquica entre professo e aluno.

Pascual (1999) nos mostra dentro dos preceitos de Piaget o papel da escola na construção da moralidade:

Piaget defende, entretanto, que o juízo moral não é inato; portanto, estará determinado pelos quatro fatores do desenvolvimento mental: maturação, experiência, interação social e regulação. É aí que entra, no nosso entender, a participação da escola no processo da educação moral dos seus alunos; pois na visão psicogenética não basta esperar, passivamente, que o aluno atinja, apenas pelo processo maturacional, o nível da autonomia moral. Pois, após uma certa fase de anomia (incompreensibilidade da obrigação moral), -determinar cronologicamente essa fase, requer uma contextualização social, histórica, cultural e educacional dos sujeitos -, a criança entende a obrigatoriedade de certos preceitos. Todavia, a obrigatoriedade decorre da autoridade do legislador; que geralmente, é represen- 
tado numa figura proeminente do contexto familiar (pai, irmão mais velho) ou do contexto escolar (professor, colega mais velho) (Pascual, 1999, p.6)

Gramsci (1982), em seu livro, coloca que a escola deveria lutar contra o que chama de folclore e ensinar de forma que os alunos aprendam que a sociedade é estabelecida pelo homem e pode ser modificada por ele, o que só é possível com conhecimentos que superem o senso comum.

Dentro das discussões que englobam a instituição escolar e seus profissionais na participação da formação do indivíduo, Libâneo (1994) destaca que:

O trabalho docente é parte integrante do processo educativo mais global pelo qual os membros da sociedade são preparados para a participação na vida social. A educação - ou seja, a prática educativa - é um fenômeno social e universal, sendo uma atividade humana necessária à existência e funcionamento de todas as sociedades. Cada sociedade precisa cuidar da formação dos indivíduos, auxiliar no desenvolvimento de suas capacidades físicas e espirituais, prepará-los para a participação ativa e transformadora nas várias instâncias da vida social (Libâneo, 1994, p. 16)

Considerando, portanto, a escola como ambiente propicio para o desenvolvimento do ser humano, individual e coletivamente, que dá a possibilidade de aprendizagem de valores éticos, morais e sociais, devemos considerar as relações existentes no dia a dia escolar, dentre elas o conflito, e a importância do professor na mediação dessas situações.

\section{CONFLITOS EM AMBIENTE ESCOLAR}

Conflitos, historicamente, têm merecido a atenção de grandes autores ao longo do tempo;Erickson abordou o conflito através do estudo das crises do desenvolvimento psicossocial; Freud, por sua vez, voltou-se para o estudo do conflito gerado pela dinâmica inconsciente entre Id, Ego e Super-Ego e Piaget revelou interesse pelo conflito resultante da falta de ajuste entre as estruturas cognitivas e a realidade (Sager\&Sperb, 1998).

No momento em que falamos em ser humano, o entendemos como um ser humano resultado de miIhões de relações que podem ser harmoniosas ou conflituosas (Guareschi, 2008). Situações de conflito são inerentes a condição humana e estão presentes em todos os meios de convívio da humanidade, sejam ele conflitos de ordem pessoal, que se baseiam na insatisfação a partir da análise e avaliação das próprias atitudes ou conflitos de ordem interativa, que estão relacionados a situações de desagrado ou discordância envolvendo outros indivíduos. De qualquer forma, os conflitos nos dão a possibilidade de analisar as situações de diferençase delas tirarmos resultados que propiciem o crescimento, desenvolvimento e amadurecimento da nossa personalidade.

Vinha (2000) expressa que o papel dos conflitos interpessoais (que aqui chamamos de interativos), são como facilitadores do conflito interno (colocados aqui como pessoais) pelo qual o indivíduo começa a levar em conta outros pontos de vista. O conflito é tomado como uma dimensão natural e inevitável da existência humana que, se for conduzido eficazmente, pode constituir uma importante experiência de desenvolvimento pessoal (Morgado \& Oliveira, 2009).

Para Costa e Silva (2010), é habitual ficarmos incomodados com a discordância, com a divergência de objetivos e de opiniões, com a ocorrência de alternativas distintas das que vislumbramos ou queremos perseguir já que nem sempre somos capazes de conviver com a incompatibilidade e integrar a diferença no 
seu sentido mais amplo e abrangente. Ressalta ainda que, contudo, esta incompatibilidade, vivida individualmente e os mais diversos grupos e organizações constitui, por um lado, uma realidade inerente às interações humanas, por outro lado, uma clara oportunidade de desenvolvimento tanto individual, como social.

Num ponto de vista - difundido pelo senso comum -, o conflito é compreendido como algo próximo ao perigoso, algo que se confunde com afrontamento, rebeldia, crise, atos de egoísmo, brigas ou, ainda, como agressividade; em outra perspectiva, o conflito é concebido, resumidamente, como movimento constitutivo dos sujeitos e de suas identidades, por meio da preservação e a afirmação do eu, sendo, portanto, realidade necessária para a formação da vida psíquica e social das crianças (Corsi, 2011).

Os conflitos estão presentes desde a infância e sendo a escola o primeiro meio de convívio das crianças fora de casa, é lá que eles aparecerão das mais diversas maneiras e pelas mais variadas razões e é na convivência com outros, sejam eles adultos ou da sua idade, que o sujeito passa a ter uma noção mais ampla de como ser portar diante de uma situação conflituosa. Se em casa os pais tendem a facilitar a atuação da criança na resolução de seus problemas, muitas vezes resolvendo eles mesmo afim de minimizar as frustrações dos filhos, na escola o ambiente favorecerá o surgimento constante de situações de conflito onde nem sempre a criança poderá ser contemplada com o que quer.

Chrispino (2007) afirma em seu trabalho que podemos esperar que, pela diferença entre as opiniões, haja conflito no espaço escolar - um conflito criado pela diferença de conceito ou pelo valor diferente que se dá ao mesmo ato e, quanto mais diversificado for o perfil dos alunos (e dos professores), maior será a possibilidade de conflito ou de diferença de opinião, isso ocorrendo dentro de uma comunidade que está treinada para inibir o conflito, pois este é visto como algo ruim. Essa concepção dentro da Educação Infantil mostra-se ainda mais intensa, já que a criança nessa idade tem concepções muito egocêntricas de como resolver situações de desconforto e desagrado, priorizando instintivamente em sua maioria resoluções que não as frustre, independentemente do sentimento gerado no outro. Dentro disto, o professor deve colocar-se como mediador da situação, sempre permitindo que a criança se expresse e ela própria entenda o significado de suas ações e as consequências, para que assim consiga ter uma postura independente e positiva diante dos conflitos vividos respeitando e reconhecendo seus colegas.

Ortega e Del Rey (2002) colocam que o conflito emerge em toda situação social em que se compartiIham espaços, atividades, normas e sistemas de poder e a escola obrigatória é um deles e complementam que, um conflito não é necessariamente um fenômeno da violência, embora, em muitas ocasiões, quando não abordado de forma adequada, pode chegar a deteriorar o clima de convivência pacífica e gerar uma violência multiforme na qual é difícil reconhecer a origem e a natureza do problema. A aprendizagem de competências de resolução de problemas deve, assim, constituir uma oportunidade para os indivíduos construírem soluções mais positivas e mas pacificas para os seus conflitos (Morgado \& Oliveira, 2009).

Costa, Almeida e Melo (2009) destacam que um dos pilares fundamentais da educação do século XXI, segundo o relatório para a UNESCO da Comissão Internacional sobre Educação para o Século XXI, consiste em aprender a ser e aprender a viver juntos, a conhecer melhor os outros e a solucionar pacifica e inteligentemente os conflitos. A convivência pode e deve ser aprendida. Ainda sobre o tema,ressaltam que a escola pode encontrar na mediação uma abordagem para a transformação criativa dos conflitos, aceitando aproveita-los como uma oportunidade de crescimento e de mudança, um potencial educativo e de formação pessoal para a resolução de problemas, atuais e futuros. 


\section{A MEDIAÇÃO, O PROFESSOR E A CRIANÇA}

Muito se tem discutido sobre o papel do professor em sala de aula e sua postura em relação aos alunos. Antigamente, o professor era visto como um ser de certa superioridade hierárquica que exigia respeito frente a sua posição e ao fato de ser ele o detentor de todo o conhecimento. Atualmente, essa postura tem sido revista e o professor passa a ser um intermediário entre o conhecimento e o aluno, estimulando-o e favorecendo a aprendizagem, de forma mais leve e que valorize o a existência e a manifestação do indivíduo, fora de uma padronização pré-concebida. As intervenções realizadas pelos educadores provocam nos educandos consequências significativas para a construção de regras e valores (Maya, 2005). Essa postura expande-se não só para o aprendizado acadêmico, mas também para todas as situações que ocorrem dentro do ambiente escolar, inclusive as de conflito. O professor passa a ser mediador, que dá às crianças ferramentas para ela mesma resolver seus problemas.

A função do professor hoje, principalmente na Educação Infantil, é de mediador dos processos de ensino e aprendizagem. Este conceito, muitas vezes, faz parte do discurso de muitos profissionais da educação e o que se tem percebido é que, na pratica, ainda há uma postura vertical em relação as crianças, ou seja, o/a professor/a ocupando a posição de detentor do saber (Santos, 2014). Lima (2003) destaca que devido a formação precária, o trabalho pedagógico dos educadores fica alicerçado no senso comum, e não numa teoria ou estudo cientifico sério e consistente.

Conflitos são inerentes à condição humana e acontecem em todas as instituições educativas, portanto o professor pode tentar evitar o surgimento de conflitos, seja realizando atividades dirigidas seja separando a turma, ou ainda intervindo rapidamente para resolver o problema; no entanto, perde-se assim a oportunidade de trabalhar valores e regras fundamentais para o convívio social (Santos e cols., 2014).

Dentro da mediação escolar, o ideal é que a papel do professor seja sempre o de buscar formas resolução que favoreçam o respeito e a compreensão do todo. A mediação, enquanto meio construtivo de resolução de conflitos oferece, pelo que proporciona aos envolvidos no conflito, um espaço ideal para desenvolver, que naqueles que desempenham o papel de mediadores, quer naqueles que como mediados trabalham em conjunto para a resolução do seu problema, a capacidade de respeito mútuo, comunicação assertiva e eficaz, compreensão da visão do outro e aceitação da diferente percepção da realidade (Morgado \& Oliveira, 2009).

A mediação de conflitos em contexto escolar, enquanto estratégia de gestão e resolução de conflitos, é precisamente uma estratégia alternativa, baseada numa metodologia que incide na relação cooperativa e em que se privilegiam a construção de soluções conjuntas, mutuamente satisfatórias para as partes em conflito, procurando que ambas saiam vencedoras, porém, por outro lado, tem como objetivo abordar o conflito numa perspectiva positiva e formadora fomentando a auto-estima, o empoderamento e a responsabilidade social. (Costa e Silva, 2010).

Em suas pesquisas Pereira e cols. (2012) e Santos e cols. (2014) consideraram através dos resultados obtidos que, de modo geral, as professoras buscam elas mesmas resolverem os conflitos por apresentar essa a forma mais simples e rápida de resolução. Em maioria, mesmo aquelas que permitiam às crianças analisar as situações, acabavam propondo maneiras pré-estabelecidas para que elas finalizassem as questões. Até mesmo quando não eram instigadas a seguir um pensamento coletivo prévio, as crianças já acionavam resoluções que consideravam melhores e mais satisfatórias para os professores. Corsi (2014) em seu trabalho ressalta que muitas crianças durante uma situação de conflito se posicionaram buscando atender uma expectativa dos adultos presentes, até mesmo reproduzindo as falas das educadoras no momento da mediação. 
Para Vygostky (1995), a continuidade do desenvolvimento cultural da criança é a seguinte: primeiro outras pessoas atuam sobre a criança; se produz então a interação da criança com seu entorno e, finalmente, é a própria criança quem atua sobre os demais e tão somente ao final começa a atuar em relação consigo mesma. Assim é como se desenvolve a linguagem, o pensamento e todos os demais processos superiores de conduta. Pascual (1999), em seu trabalho baseado no conceito de autonomia segundo Piaget, expressa:

Na medida em que ocorre a descentração, isto é, o sujeito sai do seu próprio ponto de vista para se colocar no ponto de vista do outro, ocorre uma transformação no respeito, que agora se torna mútuo. Ser governado por si mesmo, todavia, não significa a preponderância do ponto de vista pessoal, o que levaria a autonomia a um juízo moral egocêntrico; ser autônomo moralmente perante a lei ou as normas escolares quer dizer poder entendê-las como sendo o resultado de acordos entre os diversos pontos de vista dos membros que compõem um grupo e não mais como algo imutável, que transcende a vontade e o raciocínio do mesmo (Pascual, 1999, p.7).

O professor, é para criança dentro da escola a figura exemplar que ela deve seguir e imitar, inclusive nos processos conflituosos e nas interações com seus colegas. Freitas (2002), corrobora este pensamento ao colocar que a criança atribui um valor absoluto às normas, opiniões e valores desses adultos e imita os exemplos que eles Ihe dão e adota a sua escala de valores.

A injustiça por parte do professor é um quadro comum nas escolas brasileiras, e ocorre com maior frequência nos momentos de colocação de regras ou cobrança de conformidade às mesmas; se as crianças expostas à esta situação estiverem na fase de entendimento da justiça que Piaget chama de retributiva - a autoridade é a dona da verdade -, poderão entender a atitude injusta da professora como correta e reproduzi-la posteriormente (Pereira e cols., 2012). Vinha (1999), contribui para o conceito de professor autoritário quando afirma:

Autoritário é o que o adulto faz pela criança que ela pode fazer por si mesma. Autoritário é quando o professor está ensinando ou instruindo algo que a criança pode descobrir ou reinventar a partir de situações que ele vai colocando, para que ela reinvente, para que ela descubra. Autoritário, é aquele professor que coloca as normas, que diz o que é melhor para a criança. É o professor que não permite que as crianças interajam, que elas troquem ideias (Vinha, 1999, p. s/n).

Os professores precisam compreender que, embora desgastante, com o desenvolvimento da moral de seus alunos, estes cada vez menos solicitam o professor para resolver seus conflitos e essa autonomia, entretanto, só se desenvolve a partir de relações de reciprocidade e respeito mútuo entre iguais, o que implica em uma redução, ao mínimo, do poder do adulto (Pereira e cols., 2012).

Vokoy ePedroza (2005) consideram a necessidade de que a escola e todos aqueles envolvidos com a Educação Infantil tenham consciência de que suas ações têm consequências não só no momento atual do desenvolvimento da criança, como também nos posteriores pois é também nesse momento que a criança está mais propensa à formação de complexos, ou seja, atitudes que podem marcar de forma prolongada seu comportamento em relação ao meio. Sendo assim, o professor além de exemplo passa a ser protagonista do desenvolvimento psicológico do indivíduo. 
Dentro da nova visão educacional em discussão hoje no Brasil e considerando o papel do professor na formação do aluno, os educadores podem e devem promover relações cooperativas entre as crianças, incentivando a participação na resolução do problema. É a cooperação que leva a formação do sentimento genuíno de seguir uma norma por dever (e não apenas conforme o dever) e a habilidade de coordenar diferentes pontos de vista para, por exemplo, agir de maneira mais justa (Santos e cols., 2014).

\section{CONSIDERAÇÕES FINAIS}

A instituição denominada escola apresenta-se em constante mudança. Se antes era vista como um ambiente onde a criança somente recebia do professor conhecimento acadêmico e no caso de crianças em idade pré-escolar, passavam seu tempo para que os pais pudessem trabalhar, hoje sabemos que é muito mais. A escola tem como papel contribuir para a formação do indivíduo, preparando-o para a vida social e também atuando no desenvolvimento de sua personalidade.

A criança quando inicia sua vida escolar inicia também um novo processo de aprendizagem onde a interação com outras crianças permitirá que ela interaja, reconheça e entenda a existência do outro, formando assim valores morais, sociais e aspectos importantes da sua concepção de mundo e de postura diante das mais diversas situações.É na infância, convivendo que aprenderão também a lidar com seus sentimentos e frustrações, compreendendo a noção de limite.

Por ser a escola um ambiente tão rico em experiências, os conflitos facilmente surgirão. Neste momento, faz-se importantíssimo o papel do professor. É ele que mostrará as crianças como lidar com as situações conflituosas e ensinar qual a postura frente a frustração e descontentamento.

Conflitos são geralmente vistos como situações difíceis e desagradáveis, mas, se encaradas de forma construtivista, são excelentes para estabelecimento dos valores e conceitos que as crianças precisam aprender. Portanto, saber mediar e ensinar é fundamental.

É preciso levar em conta a representatividade do professor para as crianças. Sendo ele o papel de autoridade que ela reconhece dentro da escola, é dele também a maior responsabilidade na condução das resoluções dos conflitos.

Como vimos, muitas crianças seguem a conduta daquele que são exemplos para elas e muitas buscam aprovação dos adultos nas atitudes que tomam. Por essa razão, o professor deve atuar como mediador, não resolvendo ele as questões pelas crianças, mas construindo um meio favorável para que elas reconheçam as situações, entendam (dentro das limitações da faixa etária em que estão) o que suas atitudes podem causar no outro e dentro disto, decidam como agir para resolver e dessa forma, contribuir para o desenvolvimento não só intelectual daqueles indivíduos, mas também para seu desenvolvimento pessoal. Assim, contribuirá para a formação de uma sociedade melhor, formada por seres humanos capazes de analisar, decidir e atuar de forma mais justa e independente, reconhecendo seus limites e respeitando a existência de seus pares. 


\section{REFERÊNCIAS BIBLIOGRÁFICAS}

Aquino, J. G. Diferenças e preconceito na escola: alternativas teóricas e práticas. 8ª ed. São Paulo: Summuns, 1998.

Arendt, H. Entre o passado e o futuro. 3a ed. São Paulo: Perspectiva, 1992.

Brasil. Lei n. 9.394, de 20 de dezembro de 1966. Estabelece as diretrizes e bases da educação nacional. Casa da República, Brasília, DF, 20 dez. 1966. Disponível em: Acesso em: 01 nov. 2015.

Chrispino, A. Gestão do conflito escolar: da classificação dos conflitos aos modelos de mediação. Ensaio: avaliação e políticas públicas em educação. Rio de Janeiro, v. 15, n. 54, p. 11-28, jan. /mar. 2007.

Corsi, B. R. Relações e conflitos entre crianças na Educação Infantil: o que elas pensam e falam sobre isso. Educ. rev., Curitiba, n. 42, p. 279-296, dez. 2011. Disponível em <http://www.scielo.br/scielo.php?script=sci_arttext\&pi$d=$ S0104-40602011000500018\&lng=en\&nrm=iso >. Acesso em 25 out. 2015.

Coste e Silva, A. M. Conflitos e mediação em contextos educativos. Revista Galego-Portuguesa de Psicoloxia e Educación. Coruña - Espanha. v. 18, p. 7-18, 2010.

Costa, E. P., Almeira, L., Melo, M. A mediação para a convivência entre pares: contributos da formação em alunos do ensino básico. In Congresso Internacional Galelo-Português de Psicopedagogia, 5, 2009. Actas. Braga: Universidade do Minho, 2009. p. 165-178.

Dias, A.A.; Vasconcellos, V.M.R. de. Concepções de autonomia dos educadores infantis. Temas psicol. Ribeirão Preto, v. 7, n. 1, abr. 1999. Disponível em <http://pepsic.bvsalud.org/scielo.php?script=sci_arttext\&pid=S1413-389X1999000100002\&lng=pt\&nrm=iso>. Acesso em 5 nov. 2015.

Gramsci, A. Os intelectuais e a organização da cultura. 4.ed. Rio de Janeiro: Civilização Brasileira, 1982.

Guareschi, P. A. Ética e relações sociais entre o existente e o possível. In Jacques, M. G. C., et al. orgs. Relações sociais e ética. Rio de Janeiro: Centro Edelstein de Pesquisas Sociais, p. 6-11, 2008.

Libâneo, J. C. de. Didática. São Paulo: Cortez, 1994.

Lima, A. E. O. A ética e o ensino infantil: desenvolvimento moral na pré-escola. Dissertação de Mestrado, Universidade Estadual Paulista, Faculdade de Filosofia e Ciências, Marilia, SP, 2003.

Martin-Baró, I. Acción y ideología - Psicología Social desde Centroamérica. San Salvador: UCA Editores, 1992.

Maya, B. M. Educar para a administração de conflitos como via de aprofundamento da democracia. In: E. Vinyamata (Ed.), Aprendendo a partir do conflito (pp. 75-83). Porto Alegre: Artmed, 2005.

Nunes, A. O. Como restaurar a paz nas escolas: um guia para educadores. São Paulo: Contexto, 2011.

Ortega, R.; DelRey, R. Estratégias educativas para prevenção das violências; tradução de Joaquim Ozório - Brasília: UNESCO, UCB, 2002.

Pascual, J. G. Autonomia intelectual e moral como finalidade da educação contemporânea. Psicol. Cienc. prof., Brasília, v. 19, n. 3, p. 2-11, $1999 . \quad$ Disponível em: <http://www.scielo.br/scielo.php?script=sci_arttext\&pid=S1414-98931999000300002\&lng=en\&nrm=iso>. Acesso em 11 out. 2015.

Pereira, P., Marques, C. A. E., Jusevicius, V. C. C. A ação dos professores diante dos conflitos entre alunos. Revista Intellectus. Jaguariúna, v. 25, p. 215-237, 2013.

Sager, F.; Sperb, T. M. O brincar e os brinquedos nos conflitos entre crianças. Psicol. Reflex. Crit., Porto Alegre, v. 11, n. 2, p. 309-326, 1998. Disponível em: <http://www.scielo.br/scielo.php?script=sci_arttext\&pid=S0102-79721998000200010\&lng=en\&nrm=iso>. Acesso em 12 out. 2015.

Santos, D. L. dos; Prestes, A. C.; Freitas, L. B. de L. Estratégias de professoras de educação infantil para resolução de conflitos entre crianças. Psicol. Esc. Educ., Maringá, v. 18, n. 2, p. 247-254, ago. 2014 . Disponível em <http://www.scielo.br/scielo.php?script=sci_arttext\&pid=S1413-85572014000200247\&lng=en\&nrm=iso>. Acesso em 01 nov. 2015. 
Santos, L.S. A mediação do professor na educação infantil: situações de conflitos entre crianças de 4 a 5 anos. Araranguá, 2014. Dissertação (especialização em Docência na Educação Infantil) - UFSC.

Taylos, A. P.; Vlastos, G. School Zone: learningenvironments for children. Corales, New Mexico: School Zone, 1983.

Vinha, T. P. O educador e a moralidade infantil numa perspectiva construtivista. Revista do Cogeime, São Paulo, n. 14, p.15-37, jun. 1999. Disponível em: <http://www.cogeime.org.br/downloads/?arquivo=cap0214. pdf>. Acesso em: 10 out. 2015.

Vinha,T.P. 0 educador e a moralidade infantil: uma visão construtivista. Campinas: Mercado das Letras, 2000.

Vokoy, T.; Pedroza, R. L. S. Psicologia Escolar em educação infantil: reflexões de uma atuação. Psicol. Esc. Educ. (Impr.), Campinas, v. 9, n. 1, p. 95-104, jun. 2005 . Disponível em <http://www.scielo.br/scielo.php?script=sci_arttext\&pid=S1413-85572005000100009\&lng=en\&nrm=iso>. Acesso em 15 out. 2015.

Vygotsky, L. S. Obras escogidas. Madrid: Visor, 1995. t.III. 